\title{
Optimization of ultrasonically welded High density polyethylene with Medium density polyethylene
}

Vignesh Asokan ( $\square$ vigneshmech113@gmail.com )

SRM Institute of Science and Technology https://orcid.org/0000-0002-8778-3030

\section{Venkat Prasanna}

\section{Research Article}

Keywords: Holding time, weld time, frequency, mixture

Posted Date: June 16th, 2021

DOI: https://doi.org/10.21203/rs.3.rs-615324/v1

License: (1) This work is licensed under a Creative Commons Attribution 4.0 International License.

Read Full License 


\title{
Optimization of ultrasonically welded High density polyethylene with Medium density polyethylene
}

\author{
Vignesh Asokan ${ }^{1}$, Barath krishnan ${ }^{2}$, Sanjeev ravichandran ${ }^{3}$, Harish selvakumar ${ }^{4}$, Pathigulla Srihari $^{5}$ \\ ${ }^{1}$ Assistant professor,SRM Institute of science and technology,Ramapuram, Chennai, ${ }^{2-4}$ Under Graduate, SRM \\ Institute of science and technology, Ramapuram, ${ }^{5} \mathrm{VSM}$ College of engineering, AP
}

\begin{abstract}
Ultrasonic welding is a mechanical system whereby high-recurrence ultrasonic acoustic vibrations are privately connected to workpieces being held together compelled to make a strong state weld. It is usually utilized for plastics, and particularly for joining disparate materials. The point of the undertaking is to examine the quality of weld when unique materials are welded together. The sort of weld will rely upon an on-hold time, weld time, weight, and recurrence. Materials utilized will be HDPE (High Density Polyethylene) and a blend of HDPELDPE which is termed as MDPE (Medium density polyethylene). Diverse materials have distinctive properties and thus making a joint with wanted properties will give a better outcome. If one material has properties like better elasticity, pressure quality and other material have properties like pliability and flexibility and so forth then the blend of these materials will have properties of both the materials and when these kinds of materials are welded ultrasonically, they give a better outcome. Subsequently we will get a material which will give better quality with ease. Likewise, the material will be increasingly adaptable.
\end{abstract}

Index terms - Holding time, weld time, frequency, mixture.

\section{INTRODUCTION}

The project aims to analyze the joint strength of dissimilar plastic material being welded by ultrasonically. The Design of the experiment is used to select the parameter combination. The Experiment is conducted to check the feasibility of the welding dissimilar plastics and results are compared with the joint strength of similar materials. The Temperature distribution analysis is done to determine temperature distribution at the weld interface of the plastic using ANSYS software. The overall experiment helps us in analyzing the proper combination of plastic and determining the optimum welding process parameter. Ultrasonic welding is a method of bonding two-part made of the same or chemically compatible material using high-frequency ultrasonic vibration that creates a good weld. The part which is to be welded is kept between the anvil and horn which connect to the transducer, where $20 \mathrm{kHz}$ low-amplitude acoustic vibration is emitted and material melts at the point of contact where it joins. Ultrasonic welding is used in industries like process industries, electronic industries, and food packaging industries.

Real-time application of plastic welding was done during the 20th century. With the help of ultrasonic welding, the first car made entirely of plastic was assembledAltough the plastic car did not show up to be good but plastic weld was good enough to be employed. Apart from the automobile industries, it has many other useful applications.

Here the materials which will be welded will include high, low, and mixture of high and low-density polyethylene. Different parameters will be varied to get the best joint strength condition with a better combination which will help in many production industries. The welded materials will then be tested using a universal testing machine for joint strength and based on the conclusion of the results will be made.

\section{LITERATURE REVIEW}

Donald R Pattern [1], At the point of convergence of ultrasonic plastic-welding machines, is the transducer get together - here and there suggested as the "stack." The stack incorporates 3 territories: the converter, supporter, and weld horn. These parts associate together at a specific torque view and purpose of control as a resounding or vibrating contraption. The converter is the vibration source. Inside the converter are piezoelectric earth drifts sandwiched around metal plates. They are checked under high capacity to a meticulously dealt with titanium chamber. A generator supplies the high-go over electrical monstrosity to the structure control module. An affiliation supports the capacity to the converter and the piezoelectric stoneware creation broaden and contract in light of the sinusoidal, high-go over the electrical banner. Mechanical vibration to the remainder of the sections of the stack is transmitted by the titanium barrel. Around $9 \mathrm{~mm}$ evaluated zero to peak vibrations made by the converter. This isn't acceptable critical vibration to get a partition temperature for most thermoplastic tars. The assistance fortifies the data vibration, which improves the vibration at a degree depicted by the supporter structures. For example, with a 1:2.0 supporter, a 9m data would give a quantifiable vibration yield of 18 $\mathrm{m}$ around the perfection of the assistance bundle. The welding horn trades made criticalness to the thermoplastic workpieces. Mantra Prasad satpathy et al. [2], explored the joints of various unmistakable metals passed on by ultrasonic spot welding and the weld quality, interface temperature, weld an area, littler scale hardness were assessed likewise as the likelihood of the weld revealed for different weld times. As we increment the weld time, the interfacial temperature saw to be far over the recrystallization temperature, giving off an impression of being a significant disaster in joint quality. Benatar [3], considered the hypothesis of ultrasonic welding including visco adaptable warming and the capacity between close field and far-field ultrasonic welding and it explored the joint and part plan and thermoplastic material weld limit. Yeh [4], key factors influencing the welding approach and weld quality are inspected reliant on present-day applications and the decision of accommodating plastics and impact of material structure for ultrasonic welding applications are surveyed and what's more checked streamlining and examining. Lina Fadhil Kadhim [5] The mechanical and warm properties of HDPE depend on the general degrees of crystalline and questionable substances present in the polymer, significant stone structure, nuclear weight, and fanning. The properties of polyolefins have been misused by the development of various sorts of fillers to achieve charming properties at a reasonable cost. Enlargement of a filler to a polymer changes its microstructure like crystallization, glass advance, crosslinking, sort out part, and presentation, which are enduringly related to various types of nuclear enhancements. Properties of HDPE can be additionally obliged by the choice of conventional or inorganic particles into the polymer structure. HDPE is an enduring kind of material by the thickness of its carbon-carbon securities, moderate pollution is caused. HDPE's low rate of debasement is one reason that the new choice for exchange rot. Dennis Malpass [6], LDPE is portrayed by a thickness level of $0.917-0.930 \mathrm{~g} / \mathrm{cm} 3$. It isn't responsive at room temperatures, by strong oxidizing authorities, 
and a few solvents cause swelling. The temperature of $80{ }^{\circ} \mathrm{C}$ constantly and $90{ }^{\circ} \mathrm{C}\left(194{ }^{\circ} \mathrm{F}\right)$ for a brief time length, it can withstand. Its intermolecular forces (quick dipole established dipole interest) are flimsier, its versatility is lower, and its adaptability is higher. In like manner, in light of how its particles are less emphatically stuffed and less crystalline because of the side branches, its thickness is lower. When familiar with including sun masterminded radiation the plastic produces two ozone hurting substances, methane, and ethylene. On account of its low thickness properties (creating) it limits considerably more adequately after some time, affecting higher surface areas. . Right when anguished in air, LDPE produces gases at rates $\sim 2$ times and $\sim 76$ times higher than again with water for methane and ethylene, respectively. Gautam Sarkhel [7], LDPE, and HDPE have been examined. Four diverse wt parts of blends containing LDPE/HDPE were prepared. Cole-Cole plots [storage smooth thickness versus trouble relax up thickness ] and connection between most distant point separate consistency with repeat and blend technique were made. The miscibility of blends was made from rheological data. The impact nature of the blends extended with creating LDPE obsession, while determination demonstrates the opposite models. Rates of the crystallinity of the blends were coordinated by both the differential analyzing calorimetry and wide-point X-bar dispersing techniques, which show that the part of crystallinity reduced with increased LDPE center.

\section{OBJECTIVES}

1)To study the strength of joints of dissimilar plastics.

2)To reduce the cost.

3)To reduce the weight factor.

4)To make more flexible material

\section{METHODOLOGY}

Three I/p parameters to be specific holding time, weld pressure, frequency, and one $\mathrm{o} / \mathrm{p}$ parameter to be specific joint quality are picked. The information parameters set in the Ultrasonic welding machine and the yield parameter is dictated by the Universal testing machine. Analyses are directed to check the possibility of the joint quality by contrasting and divergent mix of plastics joint quality has been dictated by methods for Universal testing machine.

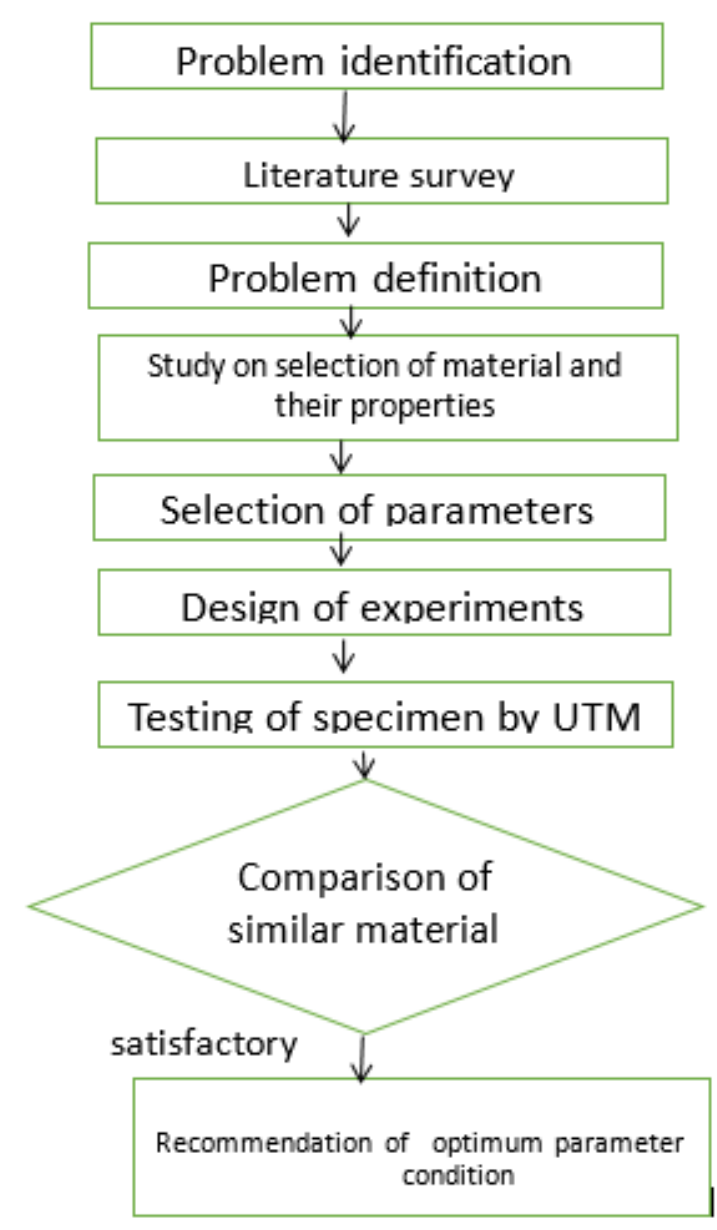

Figure 1 Methodology

\section{Material Designing}

The male and female components of HDPE, LDPE, and HDPELDPE blend are designed based on the dimensions. The dimensions are dia $35 \mathrm{~mm}$ and length $30 \mathrm{~mm}$. Figure 2 represents the $3 \mathrm{D}$ model and figure 3 represents $2 \mathrm{D}$ dimensions.

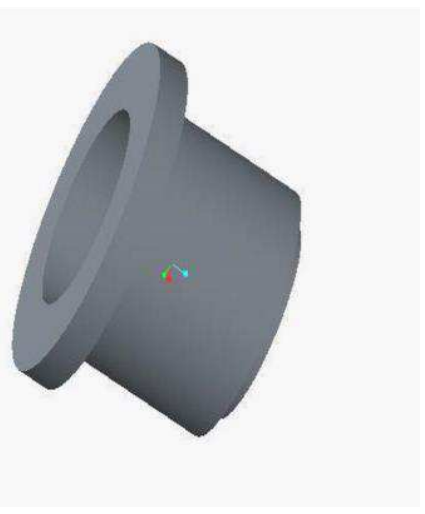

Figure-2 3D model 


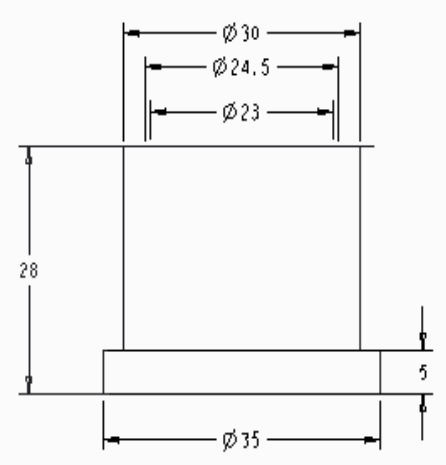

Fig 3 2D dimensions

\section{6)EXPERIMENTAL PROCEDURE}

\section{a)Experimentation}

The analyses have been led on the plastic ultrasonic welding machine. The detail of the ultrasonic welding machine has appeared in table 1. In the ultrasonic welding machine utilized here, the horn is made of ventured aluminium and an iron block is made of steel material. The plastic materials to be welded as tube-shaped shape, to be specific male part and female part are set in the apparatus. Parts are welded by methods for applying the weight by fixing the holding time and welding time. After the workpieces are being welded, the joint quality esteem is determined by a Universal testing machine. The determinations of the universal testing machine are given in table 2.

\section{b)Experimental setup}

The setup of ultrasonic welding during the welding can be seen in figure 5 below.

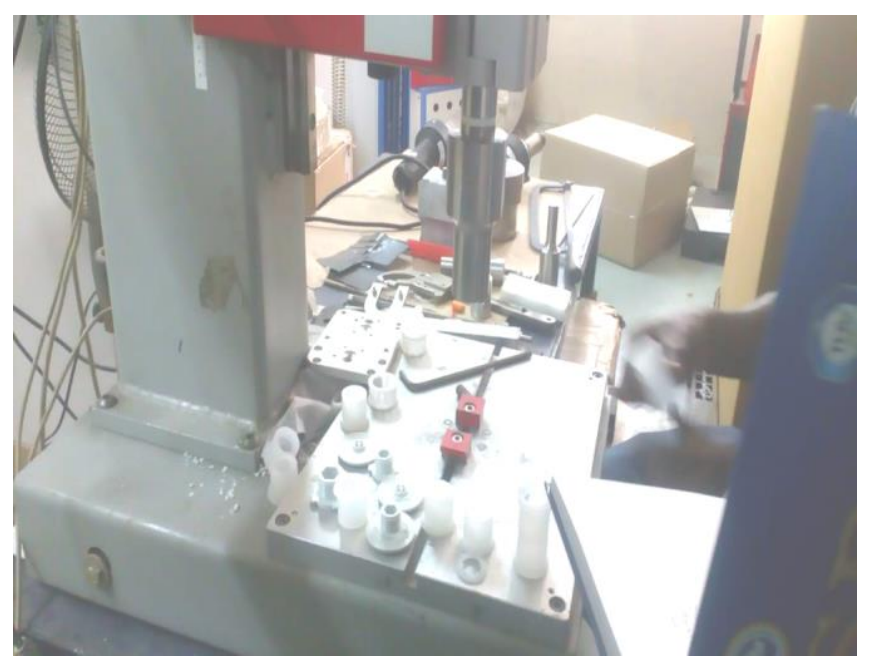

Fig 4 Ultrasonic welding machine

Specifications of ultrasonic welding machine

\begin{tabular}{|l|l|l|}
\hline S.no & Description & Value \\
\hline 1 & Make & Ultra weld, \\
& & National indosonic \\
& & \\
& & $230 \mathrm{~V} .50 \mathrm{~Hz}$ Single \\
& Phase \\
\hline 2 & Input power & $1500 \mathrm{~kW}$ \\
\hline 3 & Output power & \\
\hline
\end{tabular}

\begin{tabular}{|l|l|l|}
\hline 4 & Output frequency & $20 \mathrm{kHz}$ \\
\hline 5 & Max amplitude & 60 Microns \\
\hline 6 & Max pressure & $10 \mathrm{bar}$ \\
\hline 7 & Stroke length & $100 \mathrm{~mm}$ \\
\hline
\end{tabular}

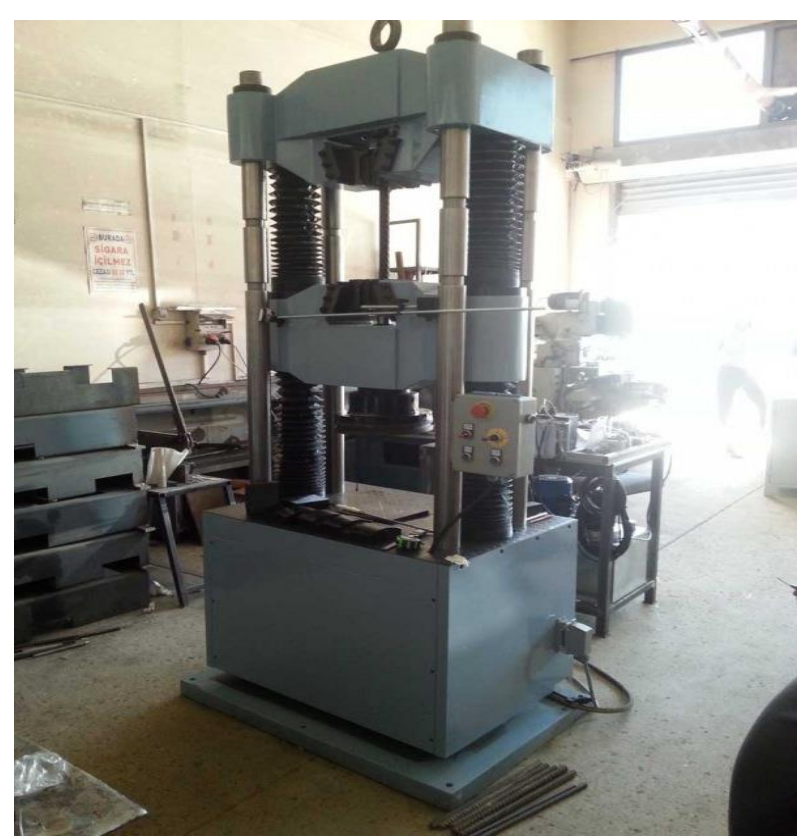

Fig 5 Universal testing Machine

Specifications of UTM

\begin{tabular}{|l|l|l|}
\hline S.No & Description & Value \\
\hline 1 & Maximum capacity & $10 \mathrm{KN}$ \\
\hline 2 & $\begin{array}{l}\text { Least } \\
\text { count } \\
\text { displacem } \\
\text { ent }\end{array}$ & $0.1 \mathrm{~mm}$ \\
\hline 3 & Accuracy of load & $\begin{array}{l}1 \% \text { indicated load } \\
\text { from } 4 \% \text { to } 100 \% \text { of } \\
\text { load cell capacity }\end{array}$ \\
\hline 4 & Grip separation & 25 to $75 \mathrm{~mm}$ \\
\hline 5 & Straining rate & $1 \mathrm{~mm} / \mathrm{mi}$ \\
& & $\begin{array}{l}\text { to } \\
100 \mathrm{~mm} / \\
\text { min }\end{array}$ \\
\hline 6 & & Single-phase, \\
& & $220 \mathrm{~V}, 50 \mathrm{~Hz}$, \\
& & AC \\
\hline 7 & Motor & $0.5 \mathrm{HP}$ \\
\hline
\end{tabular}

UTM is utilized to check the elasticity of the welded materials. Different parameters like compressive strength, ultimate strength, and so on can likewise be resolved. . At the point when the load was connected the two clasps move inverse way which prompts the detachment of the joint. The parameters were noted at which load division occurred, time was noted, and dependent on the bend all qualities determined. 
7)Design matrix and Experimental results

\begin{tabular}{|c|c|c|c|c|c|c|}
\hline \multicolumn{7}{|c|}{ Results and Statistics } \\
\hline Leng & \multicolumn{6}{|c|}{$40 \mathrm{~mm}$} \\
\hline \multirow[t]{2}{*}{$\begin{array}{c}\text { Serial } \\
\text { No. }\end{array}$} & $\begin{array}{c}\text { Sam } \\
\text { ple } \\
\text { Code } \\
:\end{array}$ & $\begin{array}{c}\text { Maxim } \\
\text { um } \\
\text { Load }\end{array}$ & $\begin{array}{c}\text { Elongat } \\
\text { ion at } \\
\text { break }\end{array}$ & $\begin{array}{c}\text { Tensil } \\
\text { e } \\
\text { Stren } \\
\text { gth }\end{array}$ & $\begin{array}{c}\text { Elongat } \\
\text { ion at } \\
\text { yield }\end{array}$ & $\begin{array}{c}\text { Modulu } \\
\text { s } \\
\text { (Autom } \\
\text { atic } \\
\text { young's } \\
\text { ) }\end{array}$ \\
\hline & & $(\mathrm{N})$ & $(\%)$ & $\begin{array}{c}\text { (MPa } \\
\text { ) }\end{array}$ & $(\%)$ & $(\mathrm{MPa})$ \\
\hline 1 & S-1 & 84.32 & $\begin{array}{l}40.4414 \\
6 \\
\end{array}$ & $\begin{array}{l}0.969 \\
22 \\
\end{array}$ & 8.98905 & $\begin{array}{l}98.1911 \\
1\end{array}$ \\
\hline 2 & $\mathrm{~S}-2$ & 95.94 & $\begin{array}{l}35.8333 \\
4 \\
\end{array}$ & $\begin{array}{l}1.102 \\
72 \\
\end{array}$ & 11.802 & $\begin{array}{l}117.359 \\
2 \\
\end{array}$ \\
\hline 3 & $\mathrm{~S}-3$ & 85.56 & $\begin{array}{l}23.9794 \\
7 \\
\end{array}$ & $\begin{array}{l}0.983 \\
43 \\
\end{array}$ & $\begin{array}{l}13.8336 \\
4 \\
\end{array}$ & $\begin{array}{l}104.137 \\
9\end{array}$ \\
\hline 4 & S-4 & 79.23 & $\begin{array}{l}29.9014 \\
7\end{array}$ & $\begin{array}{l}0.910 \\
7\end{array}$ & $\begin{array}{l}16.5310 \\
5\end{array}$ & $\begin{array}{l}21.4771 \\
8\end{array}$ \\
\hline 5 & S-5 & 90.95 & $\begin{array}{l}26.0722 \\
5\end{array}$ & $\begin{array}{l}1.045 \\
45\end{array}$ & $\begin{array}{l}19.0928 \\
8\end{array}$ & $\begin{array}{l}163.153 \\
5\end{array}$ \\
\hline 6 & S-6 & 118.27 & $\begin{array}{l}26.4764 \\
3\end{array}$ & $\begin{array}{l}1.359 \\
4\end{array}$ & $\begin{array}{l}14.3331 \\
9\end{array}$ & $\begin{array}{l}160.987 \\
4\end{array}$ \\
\hline \multicolumn{2}{|c|}{ Maximum } & 118.27 & $\begin{array}{r}46.9851 \\
2 \\
\end{array}$ & $\begin{array}{r}1.359 \\
4 \\
\end{array}$ & $\begin{array}{r}19.0928 \\
8 \\
\end{array}$ & $\begin{array}{r}163.153 \\
5 \\
\end{array}$ \\
\hline \multicolumn{2}{|c|}{ Minimum } & 79.23 & $\begin{array}{r}23.9794 \\
7\end{array}$ & $\begin{array}{r}0.910 \\
7\end{array}$ & 8.9805 & $\begin{array}{r}21.4771 \\
8\end{array}$ \\
\hline \multicolumn{2}{|l|}{ Mean } & 88.37 & $\begin{array}{r}34.5421 \\
9 \\
\end{array}$ & $\begin{array}{r}1.131 \\
32 \\
\end{array}$ & $\begin{array}{r}13.5057 \\
3 \\
\end{array}$ & $\begin{array}{r}92.5207 \\
7 \\
\end{array}$ \\
\hline \multicolumn{2}{|l|}{ Median } & 85.56 & $\begin{array}{r}29.9014 \\
7 \\
\end{array}$ & $\begin{array}{r}1.013 \\
61 \\
\end{array}$ & $\begin{array}{r}14.3331 \\
9 \\
\end{array}$ & $\begin{array}{r}104.137 \\
9 \\
\end{array}$ \\
\hline
\end{tabular}

Sample detailing which has been done at the following parameters

S1 - HDPE-MDPE $1 \mathrm{bar} / 0.5 \mathrm{sec}$

S2- HDPE-MDPE 2 bar/1 sec

S3- HDPE-MDPE $3 \mathrm{bar} / 1.5 \mathrm{sec}$

S4- MDPE-MDPE $1 \mathrm{bar} / 0.5 \mathrm{sec}$

S5- MDPE-MDPE $2 \mathrm{bar} / 1 \mathrm{sec}$

S6- MDPE-MDPE $3 \mathrm{bar} / 1.5 \mathrm{sec}$.

a) HDPE-MDPE combination

HDPE-MDPE welded components and their parameter are given below

\begin{tabular}{|c|c|c|c|c|}
\hline S.no & parameters & Level1 & Level2 & Level3 \\
\hline 1 & Weld & 1 & 2 & 3 \\
pressure(bar) & $\begin{array}{c}\text { Weld time } \\
\text { (sec) }\end{array}$ & 0.5 & 1 & 1.5 \\
\hline 3 & $\begin{array}{c}\text { Frequency } \\
\text { (Khz) }\end{array}$ & 20 & 20 & 20 \\
\hline
\end{tabular}

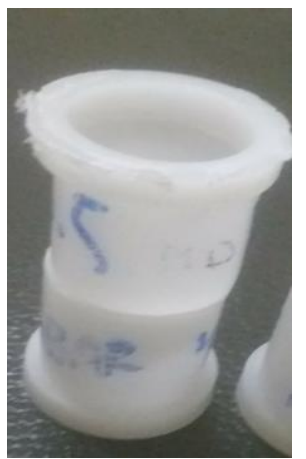

Figure 7.1 HDPE-MDPE welded specimen

c) MDPE-MDPE combination

MDPE-MDPE welded components and their parameter are given below

\begin{tabular}{|c|c|c|c|c|}
\hline S.no & parameters & Level1 & Level2 & Level3 \\
\hline 1 & $\begin{array}{c}\text { Weld pressure } \\
\text { (bar) }\end{array}$ & 1 & 2 & 3 \\
\hline 2 & $\begin{array}{c}\text { Weld time } \\
\text { (sec) }\end{array}$ & 0.5 & 1 & 1.5 \\
\hline 3 & $\begin{array}{c}\text { Frequency } \\
(\text { Khz) }\end{array}$ & 20 & 20 & 20 \\
\hline
\end{tabular}

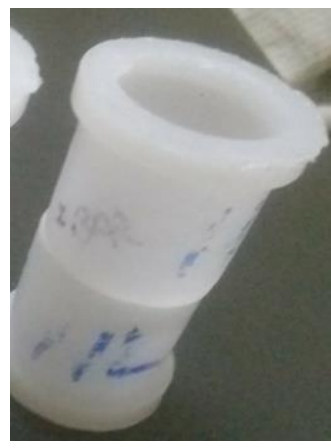

Figure 7.2 MDPE-MDPE welded specimen

\section{8)TEMPERATURE ANALYSIS FOR THE MODEL}

i) Analysis of HDPE Temperature distribution:

The temperature distribution of HDPE has been analyzed by ANSYS and it can be seen in the given figure 12 below. 


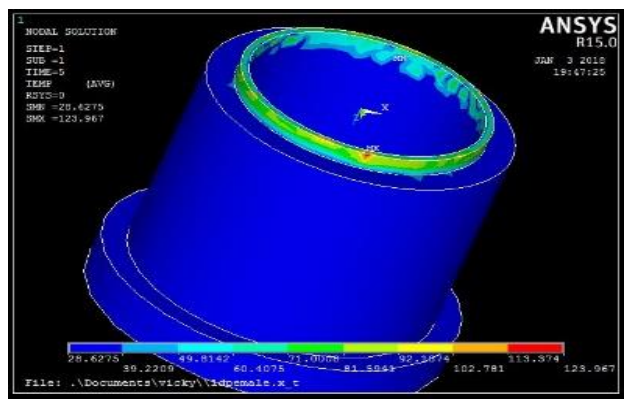

Fig 8.1. Analysis of HDPE Temperature distribution

ii) Analysis of MDPE Temperature distribution:

The temperature distribution of MDPE has been analyzed by ANSYS and it can be seen in the given figure 13 below.

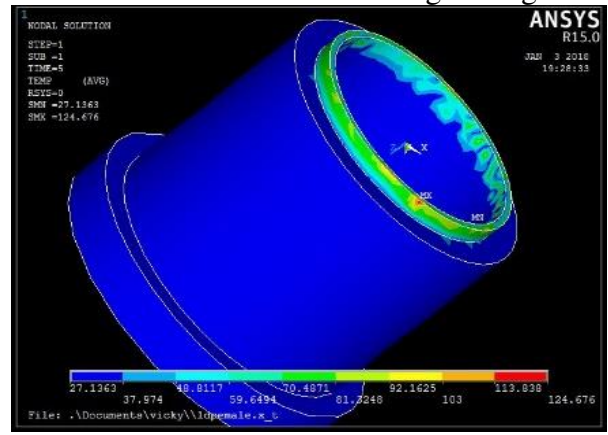

Fig 8.2. Analysis of LDPE Temperature distribution

\section{9) Result and discussion}

Performing the welding of different plastics and combination we found that the the HDPE combination was satisfactory, the weld was done easily and the strength was good but the combination of HDPE and mixture of HDPE-LDPE commonly termed as MDPE proved to be the best among all combinations with different parameters.

Based on the parameters given, the favorable pressure was 1 bar and time was 0.5 seconds. As the pressure and time were increased materials started melting or stick to the Strode, because of this some combinations failed to be joint. The highest joint strength was found to be between HDPE-LDPE (MDPE) with HDPE-LDPE (MDPE) which was $118.3 \mathrm{~N}$.

Discussion based on graphs:-

Based on the load applied different graphs were obtained which shows different physical behavior of the materials at different conditions of load applied. When specimen 1 which has a weld between MDPE and HDPE at 0.5 seconds weld time and 1 bar pressure is taken shows a graph which rises to certain values showing the region of elastic behavior and then after reaching the ultimate yield point it attains plastic behavior, if the load applied after this, the joint breaks. Hence the maximum load specimen 1 can afford without breaking the load is $84.32 \mathrm{~N}$

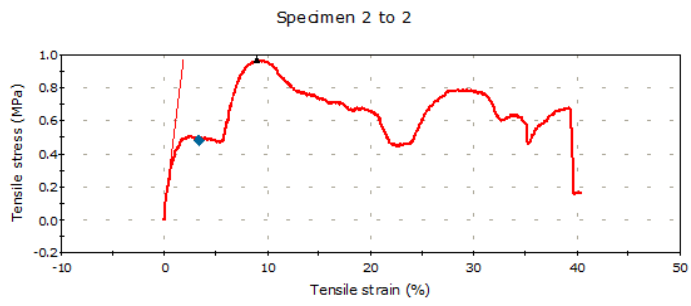

Figure 9.1: Stress vs Strain graph for HDPE - MDPE

when we see the graph of specimen 2 at 2 bar and $1 \mathrm{sec}$, we can see that the value rises to some point and then it falls down and again it rises before attaining the yield point. Specimen 2 has a maximum load of $95.94 \mathrm{~N}$.

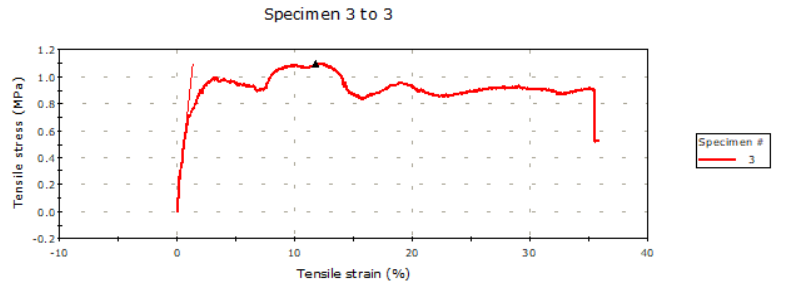

Figure 9.2: Stress vs Strain graph for HDPE - MDPE

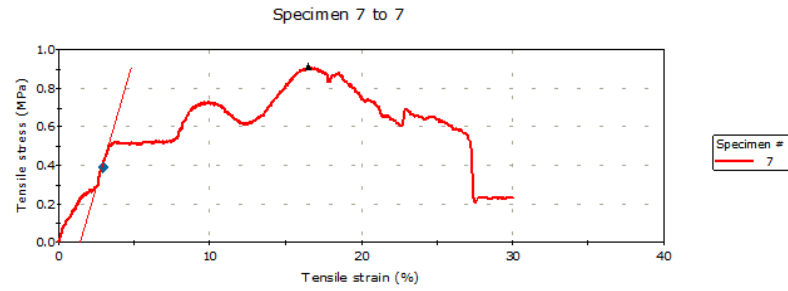

Figure 9.3: Stress vs Strain graph for MDPE - MDPE

Coming to the next category of the specimen which is between MDPE and MDPE, specimen 7 was taken with 3 bar and 1.5-sec condition which shows a graph rising to a point whose value is $79.23 \mathrm{~N}$ and then it falls showing that if the load applied more than 79.23 the joint will break down.

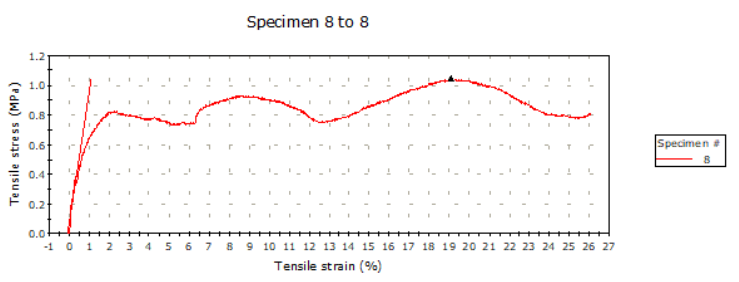

Figure 7.8: Stress vs Strain graph for MDPE - MDPE

This graph shows the curve when the condition was 2 bar and $1 \mathrm{sec}$, the maximum load it can afford is $90.95 \mathrm{~N}$ which is considered as good enough to be welded.

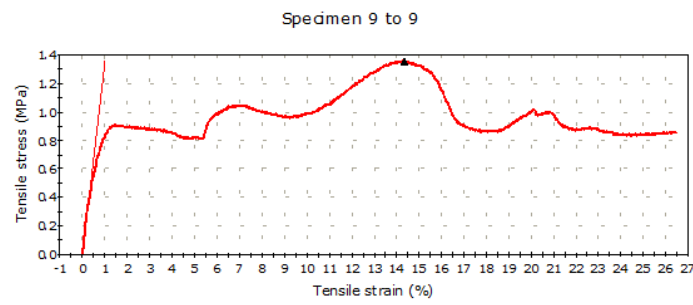

Figure 7.9: Stress vs Strain graph for MDPE - MDPE 
This graph at 1 bar and $0.5 \mathrm{sec}$ show the best result as the maximum load it can afford is $118.27 \mathrm{~N}$ which is best among all the joints and conditions performed in the experiment.

\section{0) Conclusion}

(HDPE - HDPE) combinations can be replaced employing the dissimilar combination of (HDPE + LDPE) which results in higher and effective joint strength.

Regression analysis helps in finding out the significant model terms used. The weldability of the dissimilar plastics combination LDPEHDPE is found to be more effective HDPE-HDPE.

Therefore, these findings are useful for medical sector, food packaging industries, and automobile sectors which use as input parameters such as welding time, holding time, and weld pressure. Further, optimum process parameters for dissimilar materials were also determined experimentally.

\section{1)References}

1. Umang Parmar,D H Pandya , Experimental investigation of ultrasonic welding of nonmetallic material (2016), Journal of material processing technology, pp 551-557.

2. Lina Fadhil Kadhim, Thermal and mechanical properties of H.D.P.E, (2017) pp. 2517-2526

3. Benatar, ultrasonic welding of plastics and polymeric composites (2015), Journal of ultrasonic welding ,pp 295312.

4. H J Yeh , ultrasonic welding of medical plastics (2013), Medical applications, ,pp 296322.

5. Jiromaru Tsujino, Tetsugi Ueoka, Misugi Hongoh , Masafumi Hashii, Characteristics of welding of 27,40 and 67 kilohertz ,UW systems with the help of higher resonance and fundamental frequencies (2004), pp. 131137.

6. Donald R Pattern [1], At the point of convergence of ultrasonic plastic-welding machines is the transducer get collectively.

7. Dennis Malpass [6] ,LDPE is portrayed by way of a thickness level of $0.917-0.930 \mathrm{~g} / \mathrm{cm} 3$.Gautam Sarkhel [7] , LDPE and HDPE have been examined. Four diverse wt parts of blends

8. S. Elangovan, S. Semeer, K. Prakasan, Temperature and strain distribution in ultrasonic metal welding-An FEAbased observe (2009), journal of materials processing era ,pp 1143-1150.

9. Wei Xuan Chan, Sum Huan Ng, King Ho Holden Li, WooTae Park, Yong-Jin Yoon, Micro-ultrasonic welding the use of thermoplastic-elastomeric composite movie (2016), Journal of Materials Processing Technology, pp 183-188 
Figures

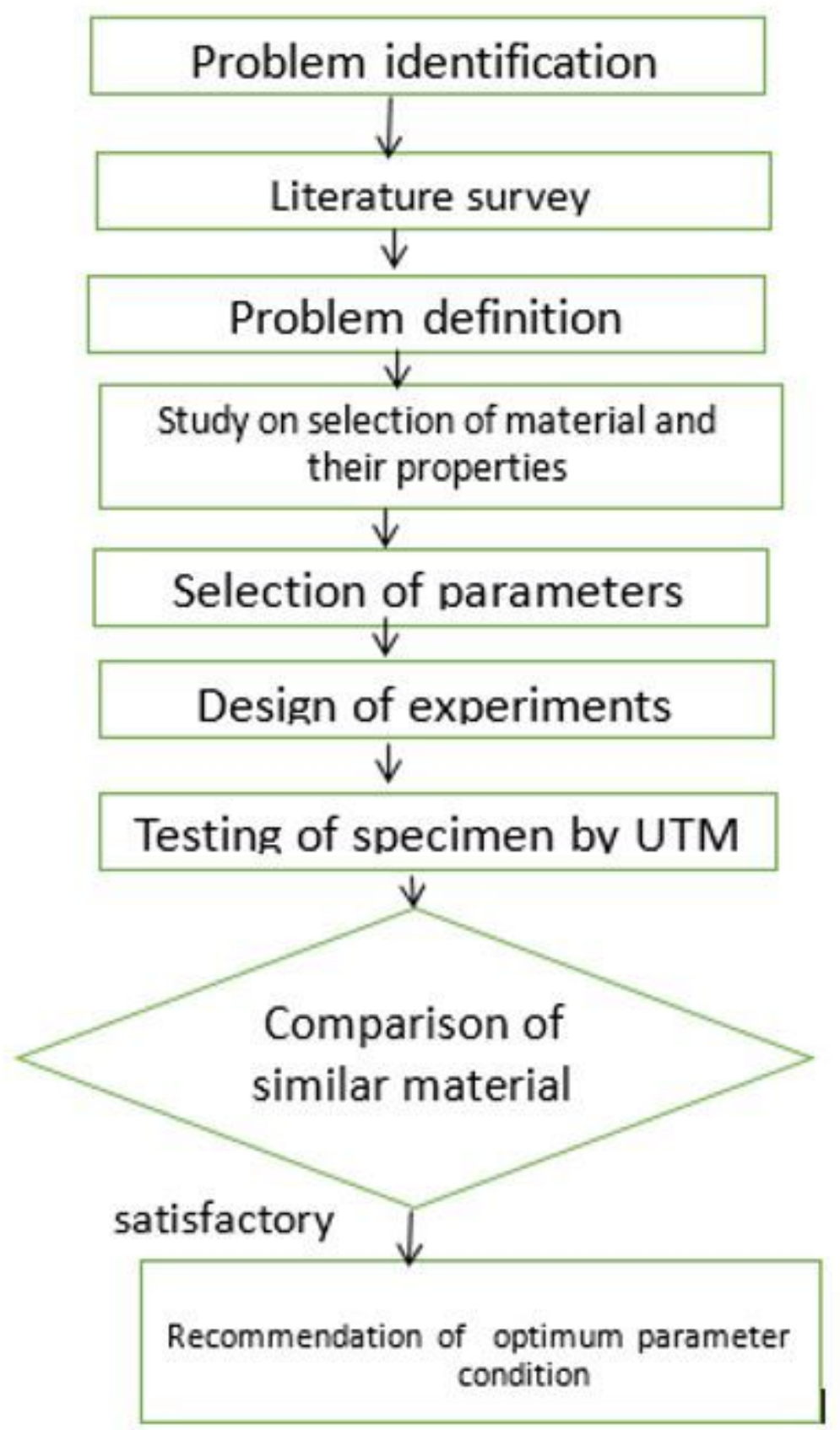

Figure 1

Methodology 


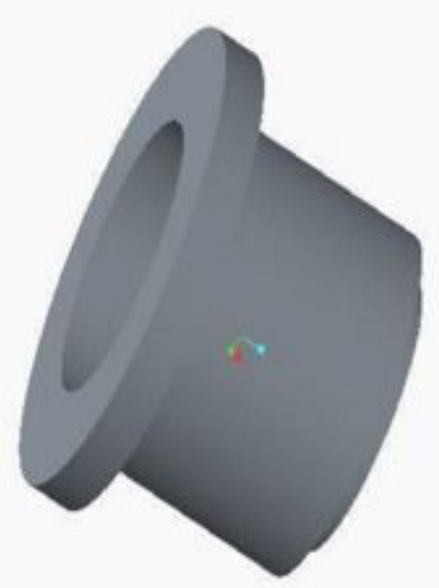

Figure 2

3D model

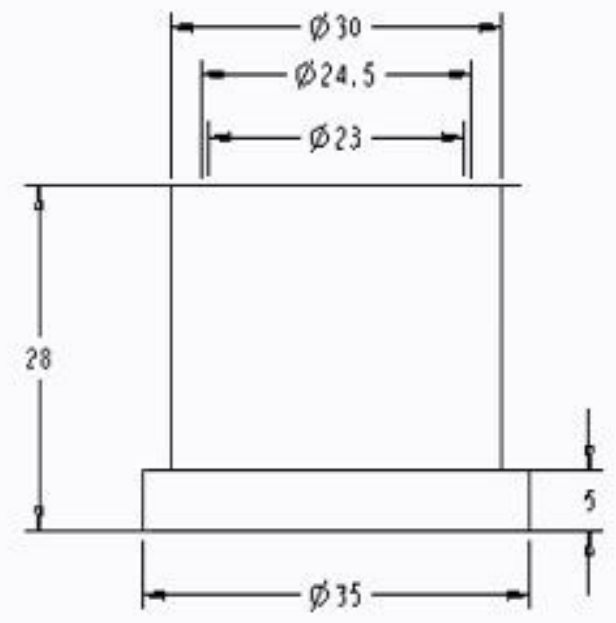

Figure 3

2D dimensions 


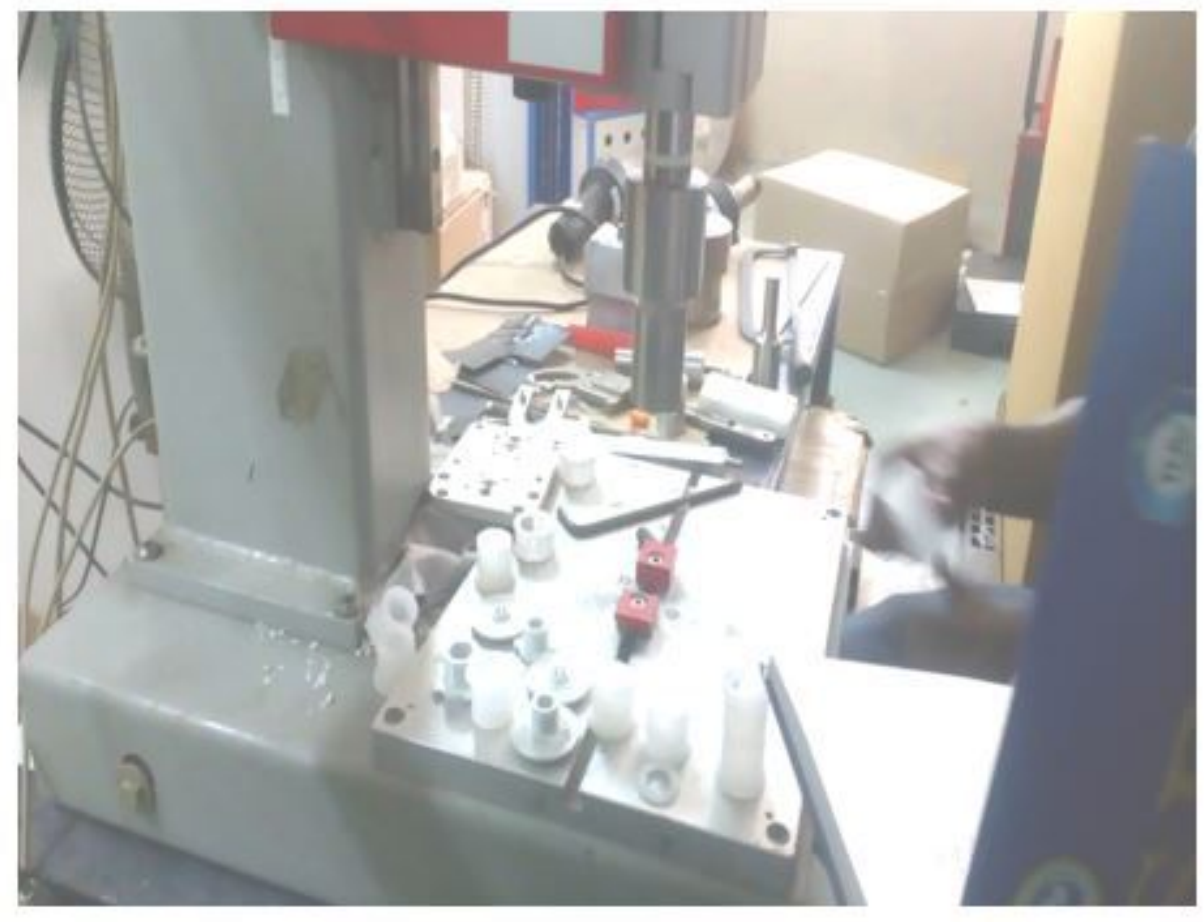

Figure 4

Ultrasonic welding machine

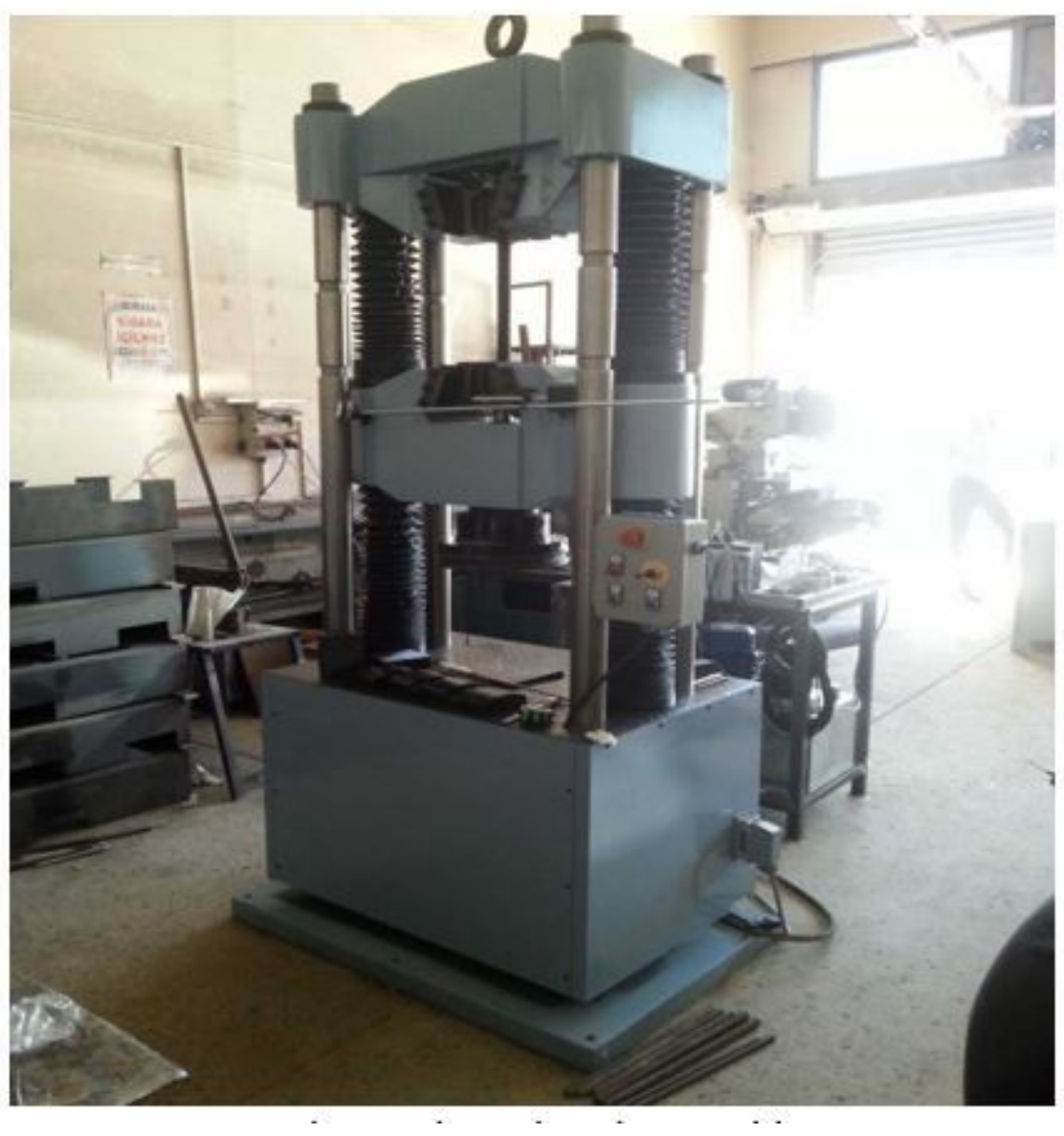


Figure 5

Universal testing Machine

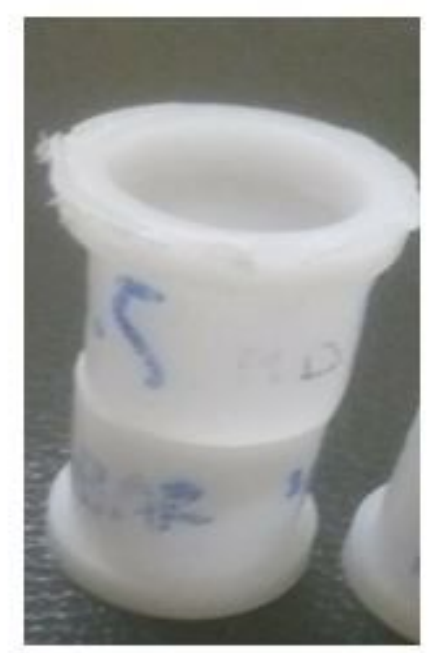

Figure 6

HDPE-MDPE welded specimen

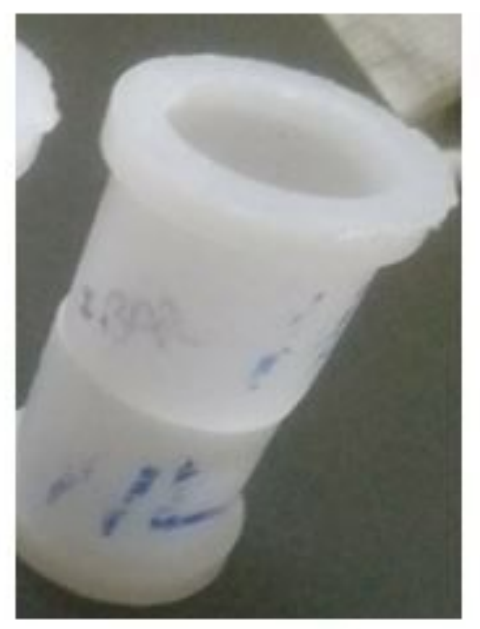

Figure 7

MDPE-MDPE welded specimen 


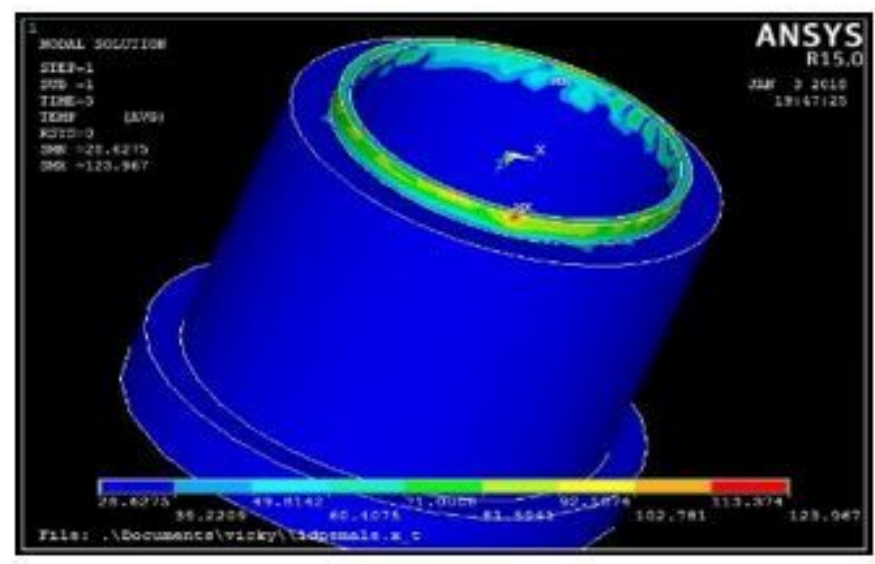

Figure 8

Analysis of HDPE Temperature distribution

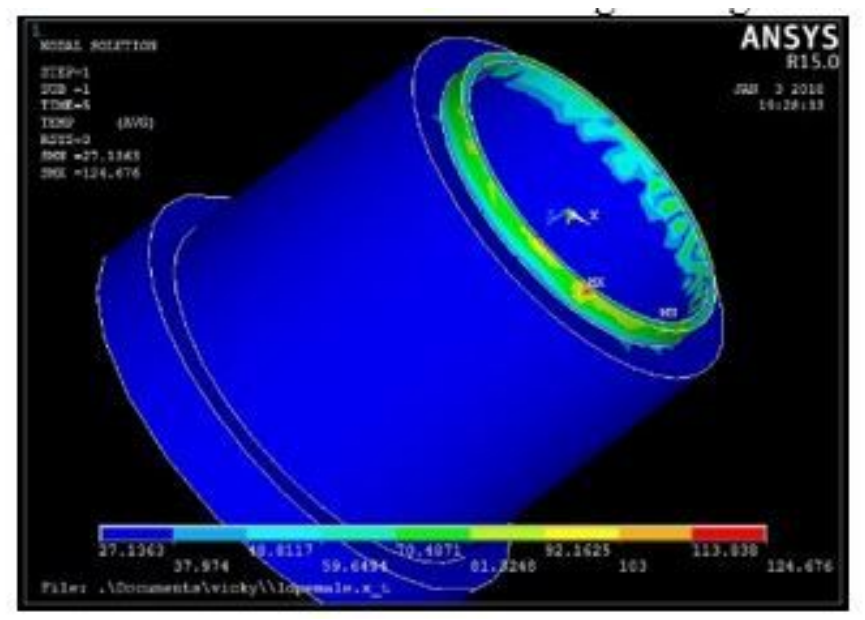

\section{Figure 9}

Analysis of LDPE Temperature distribution

Specimen 2 to 2

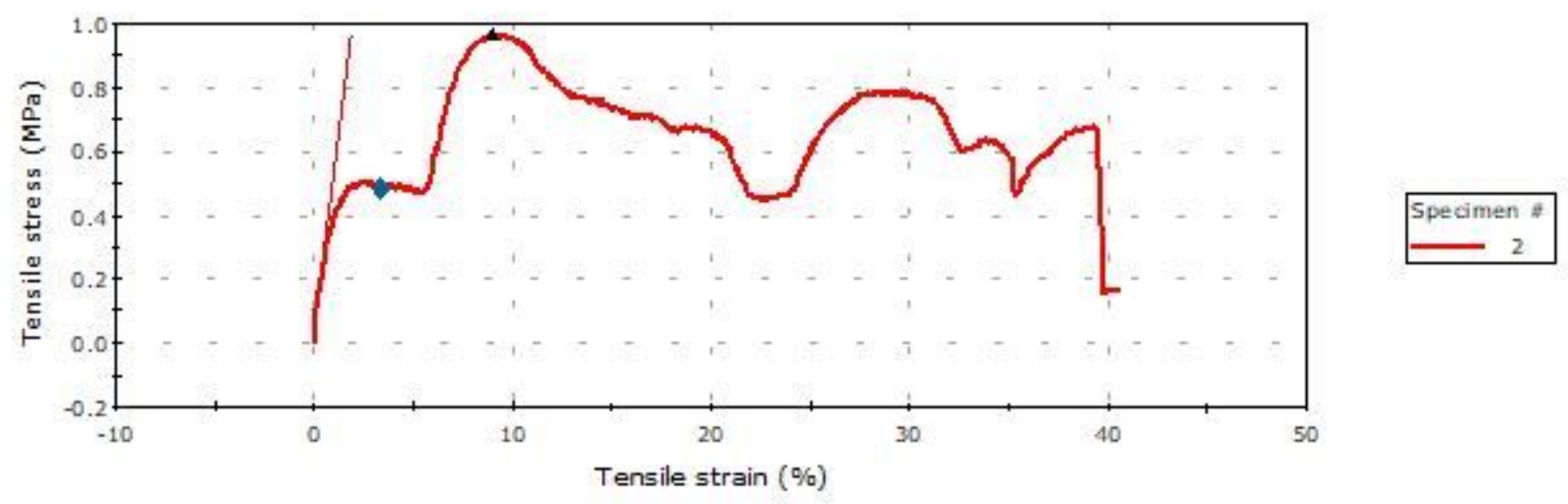

Figure 10 
Specimen 3 to 3

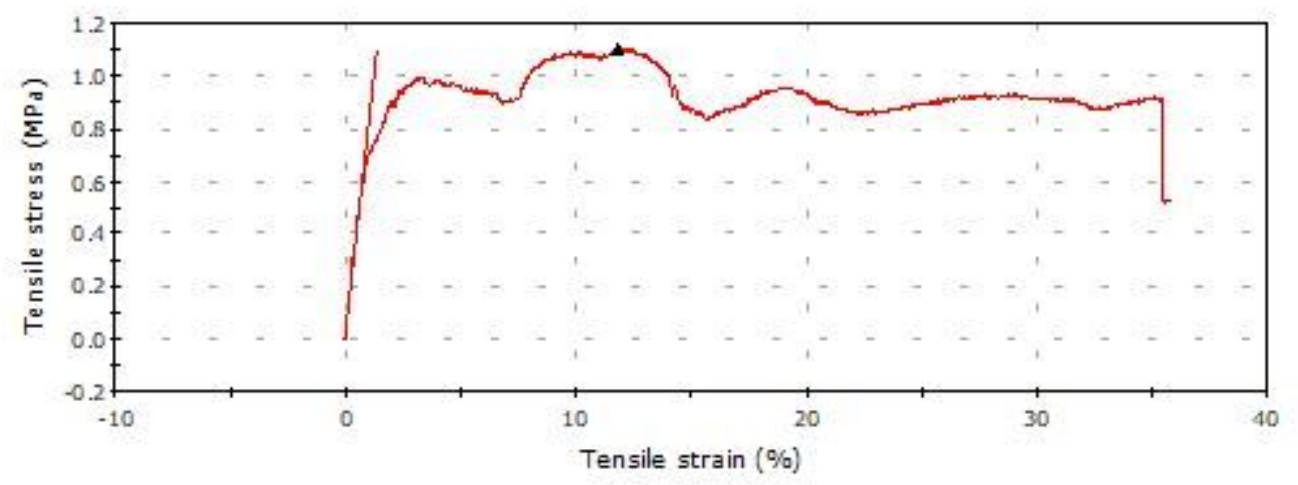

Specimen *

$-3$

\section{Figure 11}

Stress vs Strain graph for HDPE - MDPE

Specimen 7 to 7

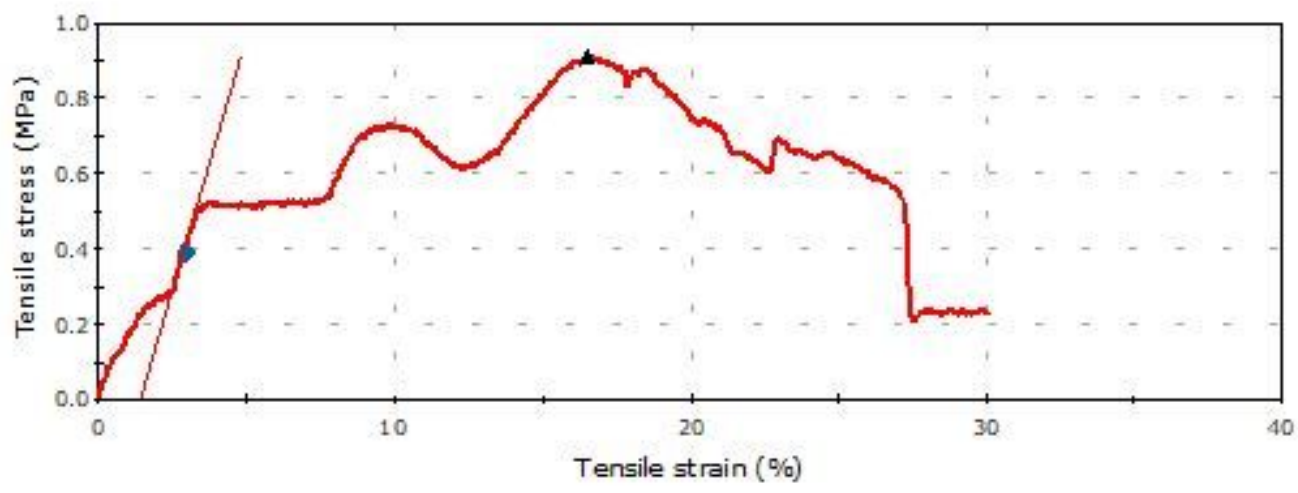

Specimen *

Figure 12

Stress vs Strain graph for MDPE - MDPE 
Specimen 8 to 8

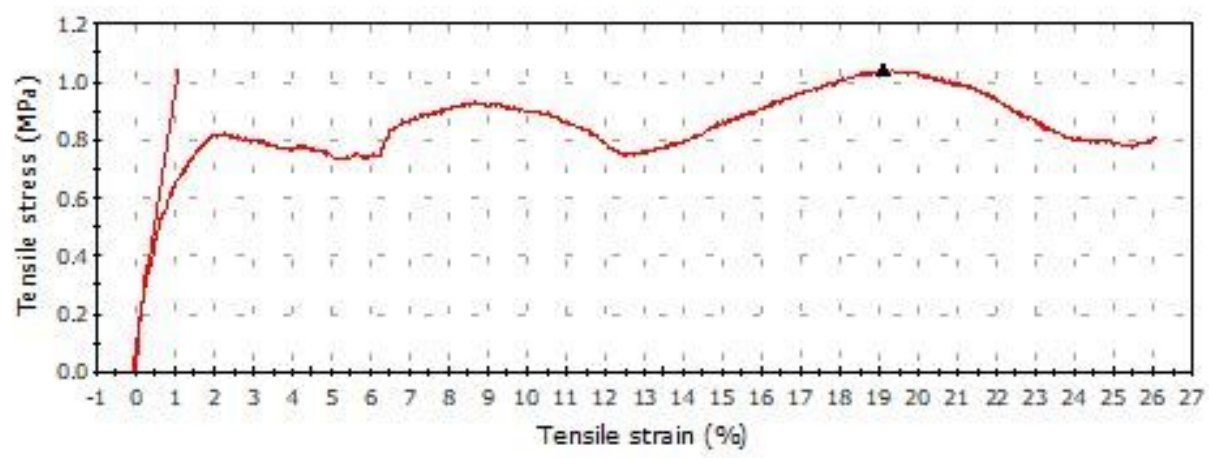

Specimen \#

- 8

Figure 13

Stress vs Strain graph for MDPE - MDPE

Specimen 9 to 9

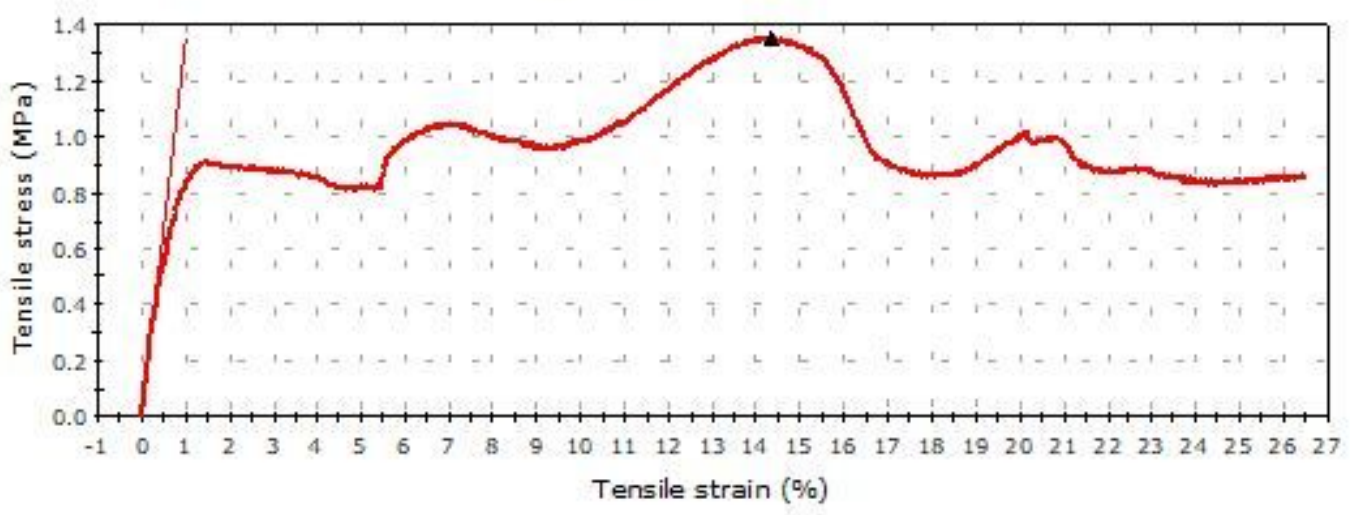

Specimen $\#$

Figure 14

Stress vs Strain graph for MDPE - MDPE 